\title{
Indicadores educacionais: uma análise frente à realidade paranaense
}

\section{Educational indicators: an analysis forward to reality of Paraná state}

Gabriela Schneider ${ }^{1}$

\section{RESUMO:}

O presente artigo apresenta alguns indicadores como: matrícula, turmas e estabelecimento, número de docentes no estado do Paraná, procurando discutir essas informações à luz da organização e política nacional. Iniciaremos com uma breve discussão sobre política educacional com foco no regime de colaboração e nas políticas de fundo, e posteriormente examinaremos os dados do censo escolar. A análise mostra a consolidação da descentralização no estado, além da discrepância entre o atendimento nas diferentes redes.

Palavras chaves: Indicadores; qualidade educacional; regime de colaboração.

\section{ABSTRACT:}

This paper presents some indicators such as enrollment, class, establishment and number of teachers in the state of Parana, discussing such data in light of the organization and national politics. Initially, a brief discussion of some points of education policy with a focus on collaborative arrangements and financial policy. After analyzing data from the school census. The analysis shows the consolidation of decentralization in the state, plus a ratherlarge difference between services in different networks.

Keywords: Indicators; education quality; system collaboration. 


\section{Introdução}

O presente artigo busca discutir alguns indicadores da educação básica paranaense a partir dos microdados coletados do Censo Escolar desde 1996. A coleta desses dados foi feita para uma pesquisa maior denominada "Remuneração de professores de escolas públicas da educação básica: configurações, impactos, impasses e perspectivas" que tem como objetivo central discutir as mudanças ocorridas no que se refere ao financiamento, à valorização e as condições de trabalho docente. Para tanto, esta pesquisa busca também analisar a realidade educacional brasileira por meio de indicadores como: acesso, turmas, estabelecimentos, número de professores, e é justamente nesses dados que esse artigo se foca, buscando analisar tais informações no estado do Paraná. Iniciaremos a discussão sobre a realidade educacional brasileira apontando aspectos da organização e financiamento da educação no Brasil, imprescindíveis para o entendimento destes indicadores.

\section{Alguns pontos sobre a educação no Brasil}

A universalização do ensino obrigatório² no Brasil é muito recente, data do início do século XX, como mostra Vieira (2009, p. 91), que afirma que "[...] o Ensino Fundamental foi praticamente universalizado, grandes desafios persistem em relação à oferta de Educação Infantil e de Ensino Médio [...]". Ainda que se tenha clareza da necessidade de ampliar o atendimento na educação infantil e no ensino médio, percebe-se a necessidade de discutir a forma como se dá a oferta da educação no Brasil, haja vista a interferência significativa na qualidade.

A educação brasileira nunca apresentou um regime centralizado, como mostra Souza (2003), ao contrário, desde 1834 divide-se a responsabilidade da educação entre o governo central e os estados (na época províncias), tais ações promoveram um descaso frente à educação, mediante a obrigatoriedade das províncias em regulamentar e promover a educação primária e secundária. É o que afirma Romanelli:

[...] A falta de recursos, no entanto, que um sistema falho de tributação e arrecadação de renda acarretava, impossibilitou as províncias de criarem uma rede organizada de escolas. 0 resultado foi que o ensino, sobretudo o secundário, acabou ficando nas mãos da iniciativa privada e 0 ensino primário foi relegado ao abandono, com pouquíssimas escolas, sobrevivendo à custa do sacrifício de alguns mestres-escolas, que destituídos de habilitação para o exercício de qualquer profissão rendosa, se viam na contingência de ensinar. (ROMANELLI, 1987, p. 40).

Esse pequeno relato é um dos elementos que colaboram com o entendimento do por quê a educação brasileira ter demorado tanto tempo para conquistar avanços significativos no que se refere ao atendimento da educação obrigatória e da necessidade de melhoraria nos índices em outras etapas da educação básicas e suas modalidades, bem como no ensino superior. Ainda sobre esse tema afirma Cury:

Iniciava-se, em um país imperial e centralizado, uma descentralização educacional e, com ele, uma duplicidade de sistemas de ensino sem a constituição de um sistema nacional. De um lado, os poderes gerais (Corte), com impostos mais elevados, jurisdicionaria o ensino superior, apanágio das elites, e, de outro lado, a instrução primária ficaria a cargo das Províncias, titulares de impostos de menor valor. Data dessa época o já conhecido "empurra-empurra" quanto a uma clareza maior das competências e do financiamento. (2008, p.1197).

Desde esse período o Brasil manteve basicamente um regime descentralizado, que aliado as grandes divergências sociais e políticas no país contribuíram e contribuem para uma oferta educacional desigual, sendo que as regiões e as camadas mais pobres são as que mais sofrem com esse sistema. Para Romanelli (1987) as mudanças industriais e educacionais, além de chegarem com 100 anos de atraso ao Brasil, se expandiram de forma diferente em vários estados e regiões do país. Oliveira, ao discorrer sobre a realidade brasileira, aponta para suas diferenças, afirmando que, em termos educacionais:

Se tomarmos como referência a ideia de um estado que garanta um padrão mínimo de qualidade para todos os cidadãos, ao pensarmos a desigualdade nacional, verificamos que no Brasil a tensão entre federalismo e desigualdade em educação se acentua [...] (OLIVEIRA, 2003, p. 151).

2 Referimo-nos ao ensino fundamental como obrigatório. Desde, 2009, porém o ensino se tornou obrigatório dos 4 aos 17 anos. 
A constituição de 1988 manteve a ideia da descentralização e legislou um regime de colaboração entre União, Estados e Municípios, ampliando a esfera de responsabilidade para os municípios, que, até então, colaboravam na oferta educacional, mas não a tinham como responsabilidade direta.

A União, os Estados, o Distrito Federal e os Municípios organizarão em regime de colaboração seus sistemas de ensino. § $1^{0} \mathrm{~A}$ União organizará o sistema federal de ensino e o dos Territórios, financiará as instituições de ensino públicas federais e exercerá, em matéria educacional, função redistributiva e supletiva, de forma a garantir equalização de oportunidades educacionais e padrão mínimo de qualidade do ensino mediante assistência técnica e financeira aos Estados, ao Distrito Federal e aos Municípios; $§ 2^{\circ}$ Os Municípios

atuarão prioritariamente no ensino fundamental e na educação infantil. $\S 3^{\circ}$ 0s Estados e 0 Distrito Federal atuarão prioritariamente no ensino fundamental e médio. Na organização de seus sistemas de ensino, a União, os Estados, o Distrito Federal e os Municípios definirão formas de colaboração, de modo a assegurar a universalização do ensino obrigatório. (BRASIL, 1988, art. 211, grifos nossos).

A descentralização em si não é o único problema da educação brasileira, Cury aponta que um dos nós se dá no fato do ato adicional de 1834 ter criado vários sistemas sem a consolidação de um sistema único, ou seja, um sistema nacional que fosse capaz de garantir igualdade e qualidade na oferta e no atendimento educacional. Para que um sistema nacional seja construído necessário políticas de Estado e não de governo como é característico no país, bem como definição clara de diretrizes e bases da educação nacional. Além disso, é imprescindível que o regime de colaboração, realmente, se consolide que as leis sejam cumpridas e que a União se responsabilize mais com a educação básica, como mostra Saviani (2008).

Para reformar o ensino no Brasil, de acordo com as orientações de organismos internacionais, o governo de Fernando Henrique Cardoso propõe uma reforma na política e, consequentemente, na educação brasileira. Tais mudanças, segundo Peroni (2003) estavam ligadas ao discurso de que havia dinheiro, mas era mal aplicado, com isso propôs a criação do Fundo Nacional de Desenvolvimento da Educação Básica e a Valorização do Magistério (FUNDEF³).

Com esse fundo, o governo busca diminuir as desigualdades brasileiras, além de cumprir com seu papel redistributivo e supletivo, ao passo que o FUNDEF estabelecia um custo/aluno anual, no qual não poderia ser inferior em nenhum estado quando da distribuição dos recursos pelo número de matrículas do estado. Tal fundo, porém, não ficou livre das artimanhas políticas e do descumprimento da lei, afinal

Todos os estados deveriam gastar pelo menos a média nacional, contanto para tal com a suplementação da União. Aí reside a controvérsia. Em 97, a União trabalhava com a ideia de que o gasto médio nacional seria de $\mathrm{R} \$ 300,00$, mas 0 Fundo só começa a vigir a partir de 98. No segundo semestre de 1997, houve uma experiência de implantação no Pará e outra no Ceará, neste último, apenas para alguns municípios. Apenas a partir de 98, é que o Fundo vigorou para o Brasil todo. Desde então, o governo federal subestimou o valor da média nacional. 0 que acontece? Se a média nacional fosse maior, o montante a ser complementado pela União para os estados seria maior. Quando diminui essa média, tanto o número de estados abrangidos pela suplementação federal é menor, quanto 0 montante da complementação [...], em 1998, o valor fixado pela União para 0 gasto/aluno/ano/nacional, de $\mathrm{R} \$$ 315,00, estaria abaixo do estipulado na lei. Em 1998, o governo federal complementou, em valores de 98, R\$ 486 milhões para 0 Fundef. Se a média nacional de gasto fosse de $R \$ 419,00$ esse valor seria de aproximadamente $R \$ 1.500$ milhões e, evidentemente, abrangeria mais estados. (OLIVEIRA, 2003, p.148).

Apesar de não diminuir as desigualdades entre as diversas regiões do país, o fundo colaborou, significativamente, para a municipalização das matrículas do ensino fundamental, bem como a universalização dessa etapa da educação básica, por um processo denominado por Cury (2002) de focalização, que acabou diminuindo os investimentos na educação nas outras etapas, bem como na EJA (Educação de Jovens e Adultos) cujo cômputo de matrículas para efeitos de recebimento de recursos foi vetado e retirado do fundo.

30 FUNDEF é um fundo de natureza contábil, que foi criado pela Emenda Constitucional no 14 e regulamentado pela Lei n. 9.424, de dezembro de 1996. 0 "fundo redistribuiu, em âmbito estadual, entre 0 governo estadual e os municipais, uma parte dos impostos que já eram vinculados à MDE antes da criação do Fundo, com base no número de matrículas no ensino fundamental regular das redes de ensino estadual e municipais" (DAVIES, 2006). 
Dada a flagrante diminuição da receita para os atendimentos que não do ensino fundamental regular priorizado pelo FUNDEF, os municípios das Regiões Sul e Sudeste, passaram a se perguntar sobre quem atender: às crianças na faixa da educação infantil ou aos jovens e adultos de baixa escolaridade? A escolha, como se infere, não tem sido fácil. (ARELARO; KRUPPA, 2007, p. 99).

Ainda em relação ao processo de municipalização, pode-se dizer que a participação da rede pública aumentou drasticamente no período posterior à implementação do FUNDEF4, Pinto (2007) assim analisa esse fenômeno:

[...], se no período de 1991 a 1996 as matrículas municipais respondiam por cerca de 37\% do total da rede pública, com a entrada em vigor, a partir de 1997, do Fundo de Manutenção e Desenvolvimento do Ensino Fundamental e de Valorização do Magistério (FUNDEF), nota-se um progressivo aumento da participação da rede municipal, que chega em 2006 atendendo 52\% das matrículas públicas. (PINT0, 2007, p.890)

O FUNDEF vigorou até 2006 quando foi substituído pelo Fundo de Valorização da Educação Básica e Valorização do Magistério (FUNDEB), o fundo de natureza contábil visava a corrigir alguns problemas do antigo fundo, um deles referia-se, justamente, a inclusão das outras etapas e modalidades da educação básica, bem como a ponderação de acordo com a localização ou mesmo a etapa/modalidade. Além disso, parece haver uma melhora na definição do custo/aluno, mas insuficientes, especialmente nos quatro primeiros anos de vigência do fundo, como mostra Davies (2003), que comenta ainda que,

A principal fragilidade do FUNDEB, assim como a do FUNDEF, é que traz poucos recursos novos para o sistema educacional como um todo, uma vez que apenas redistribui $20 \%$ de grande parte dos recursos que já são constitucionalmente vinculados à educação, entre 0 governo estadual e as prefeituras, com base no número de matrículas na educação básica, o que significa que uns governos ganharão, mas outros perderão na mesma proporção, sobretudo quando não houver complementação federal, que será o único recurso novo para 0 sistema educacional como um todo, que não é tão significativo assim, como veremos adiante. 0 que é mais grave ainda é que, projetando as conclusões do estudo de Bremaeker (2003) mencionado acima para o FUNDEB, podemos prever que ele prejudicará milhares de municípios (2.185 no caso do FUNDEF em 2002) com população menor e, portanto, receita própria (IPTU, ISS, ITBI) ínfima e mais dependentes o FPM, que tenderão a perder com o FUNDEB. (DAVIES, 2003, pp. 762-763).

Percebe-se, então, que os dois fundos, mesmo que tenham efeitos positivos, não representam maiores investimentos no campo da educação, e apesar do FUNDEB ter ampliado o alcance para toda a educação básica, o dinheiro ainda é insuficiente, a EJA, por exemplo, recebe uma ponderação de 0,70 do valor do fundo, o que, ainda, mostra um descaso para com algumas etapas e modalidades. Além disso, a creche só foi incluída graças à luta de movimentos organizados, pois, inicialmente, ela não se encontrava presente na redistribuição do dinheiro no fundo. Manteve-se as diferenças regionais, afinal os valores do custo/aluno ano continuam muito discrepantes.

Permanece uma diferença significativa entre 0 menor e o maior custo-aluno estadual. Esta diferença vem caindo principalmente pela injeção de recursos maiores da União, que provoca uma elevação do custo-aluno nos estados mais pobres, aproximando-os dos estados com melhor arrecadação. Em 2008 a diferença era de 2,26 vezes e em 2009 será de 2,14 vezes. Numa ponta encontramos Roraima (R\$ 2.890,08) e Espírito Santo (R\$ 2.466,46) e no outro extremo temos nove estados (Alagoas, Amazonas, Bahia, Ceará, Maranhão, Pará, Pernambuco, Paraíba e Piauí) que precisam da União para chegar ao valor de $\mathrm{R} \$ 1.350,09$. (ARAUJ0, 2009).

Outro ponto chave do FUNDEF e também do FUNDEB refere-se à questão da valorização docente. Os professores brasileiros ganham menos que seus colegas servidores, e menos que professores de outros países, possuem carreira pouco estimulante e há uma grande diferença salarial em âmbito nacional. Nesse sentido os fundos tinham e têm como objetivo melhorar a carreira do magistério, ao analisar os impactos do FUNDEF podese dizer que

[...] os objetivos previstos de melhoria salarial docente e redução das desigualdades de recursos per capita não foram alcançados. A melhoria das condições de trabalho dos profissionais da educação por meio de sua valorização salarial ocorreu somente em algumas regiões do país, nas redes municipais, principalmente naquelas que apresentavam salário mínimo nacional inferior ao salário mínimo

4 Para maiores informações sobre os impactos do FUNDEF ver PINTO (2007). 
nacional. Em outros casos, a melhoria ocorreu por meio de abonos, bonificações, prêmios entre outras modalidades de complementação salarial. (ARELAR0, 2007, p. 12).

Ainda sobre a questão docente é possível afirmar que:

Essa relação entre tributos, matrículas e salários de professores/as ficou explícita a partir da vinculação entre a arrecadação de impostos e sua destinação à educação pública, tal como ocorre no Fundo de Manutenção e Desenvolvimento do Ensino Fundamental e de Valorização do Magistério (FUNDEF), criado em 1996, em que 60\% das verbas são destinadas exclusivamente para o pagamento de docentes em exercício, e permanece no Fundo de Manutenção e Desenvolvimento da Educação Básica e de Valorização dos Profissionais da Educação (FUNDEB), criado em 2007. Nesta perspectiva, o aumento do número de matrículas implica em um maior número de professores/as, ocasionando uma maior divisão dos fundos públicos que resulta em salários menores, devido às opções governamentais que raramente seguem na direção de aumentar os recursos vinculados à educação pública. (ROCHA, s/d, p.2).

É nesse contexto de organização e financiamento da educação, que Oliveira e Ferreira (2007) explicitam a crise da escola brasileira, crise que não se restringe à educação, mas a todo o sistema social, que acaba impactando sobre a sua valorização e de seus profissionais, sobre a qualidade e sobre o percurso. Ciente disso iremos analisar a realidade da educação no Estado do Paraná.

\section{Analisando a realidade paranaense}

Um dos primeiros indicadores para se analisar é o acesso, afinal a educação é considerada direito de todos os brasileiros, o artigo $6^{\circ}$ da constituição a coloca como direito social, nesse sentido, logo deve ser garantida a todos pelo Estado (BRASIL, 1988). Porém, no caso brasileiro, esse direito ainda não se consagrou a todos, afinal em 2005, o Brasil ainda contava 11,05\% da população analfabeta com15 anos ou mais (VIERA, 2009).

O ensino fundamental está universalizado, mas a educação infantil ainda precisa ampliar e, muito, seu atendimento. "Vale lembrar que considerando a faixa etária a que se destina a Educação Infantil, apenas 13\% das crianças de 0 até 3 anos e 72\% das crianças de 3 a 6 anos frequentam a escola." (VIERA, 2009, p. 96). Essa discrepância no atendimento pode ser percebida no estado do Paraná, onde se vê um número maior de matrículas na pré-escola do que na educação infantil, o mesmo pode ser percebido nos estabelecimentos, como demonstra o gráfico 01 :

\section{Gráfico 1 - Estabelecimentos de educação infantil públicos no Paraná.}

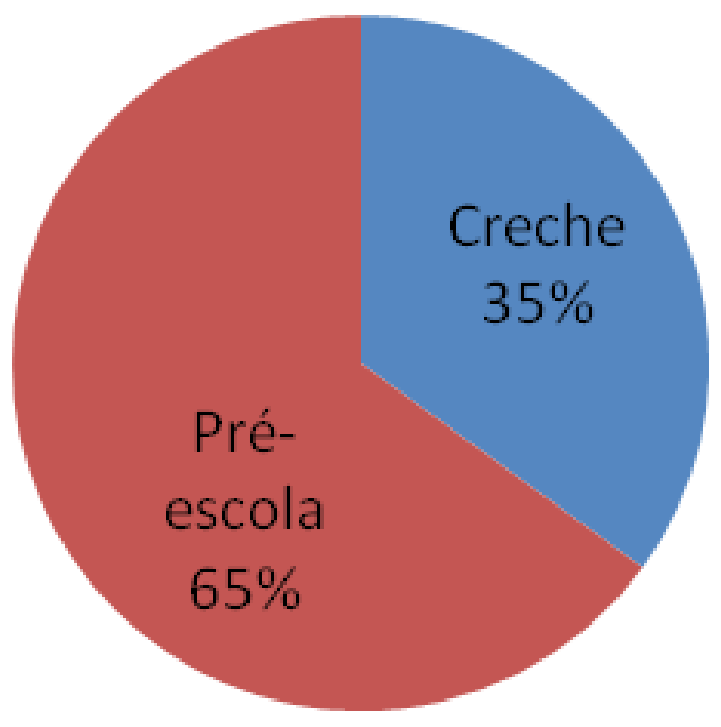

Fonte: Microdados do Censo Escolar (2009), dados coletados pela autora. 
Souza e Damaso (2007) ao analisarem a cobertura da oferta da educação infantil na Região Metropolitana de Curitiba, Londrina e litoral apontaram para o déficit no atendimento da dessa etapa de ensino, salientando, especialmente a questão da creche em relação à pré-escola:

Na rede pública temos um aumento de cobertura de 18,6\% em 2001 para 26,0\% em 2006. Em 2001, a rede pública atendia 55.147 crianças o que correspondia a 11,3\% da população infantil desta faixa etária e a rede privada 31.746 crianças que equivale a 7,2\%. Até 2006, houve um aumento de cobertura na rede pública resultando em 15,2\% que corresponde a 72.642 crianças, enquanto na rede privada 0 a cobertura continuou a ser de 7,2\%, atendendo a 34.364 crianças. (SOUZA e DAMASO, 2007, p. 37).

Ao analisar esses dados pode-se perceber que, apesar do número de estabelecimentos na educação infantil de Curitiba ter apresentado um crescimento, passando de 2094 estabelecimentos em 1996 para 4055, em 2009 (CENSO, 2006, 2009). Esse crescimento ainda é insuficiente para atender a demanda. Atualmente a rede pública paranaense atende 222.191 crianças de 0 a 5 anos, como se pode perceber na tabela 1.

\section{Tabela 1 - Comparativo das matrículas públicas na educação infantil - PR}

\begin{tabular}{|c|c|c|c|c|c|c|c|}
\hline & & & 1996 & 2000 & 2004 & 2007 & 2009 \\
\hline & & Creche & & 49 & 84 & 44 & 90 \\
\hline \multirow{10}{*}{ Educação Infantil } & Federal & Pré-escola & 262 & 26 & 79 & 63 & 38 \\
\hline & & Total & 262 & 75 & 163 & 107 & 128 \\
\hline & & Creche & & 82 & 101 & 3 & 0 \\
\hline & Estadual & Pré-escola & 7.316 & 4.200 & 1.532 & 523 & 280 \\
\hline & & Total & 7.316 & 4.282 & 1.633 & 526 & 280 \\
\hline & & Creche & & 60.289 & 66.375 & 83.725 & 91.779 \\
\hline & Municipal & Pré-escola & 103.918 & 149.935 & 172.282 & 131.663 & 130.004 \\
\hline & & Total & 103.918 & 210.224 & 238.657 & 215.388 & 221.783 \\
\hline & & Creche & 0 & 60.420 & 66.560 & 83.772 & 91.869 \\
\hline & Público & Pré-escola & 111.496 & 154.161 & 173.893 & 132.249 & 130.322 \\
\hline & & Total & 111.496 & 214.581 & 240.453 & 216.021 & 222.191 \\
\hline
\end{tabular}

FONTE: MICRODADOS CENSO ESCOLAR (1996; 2000; 2004; 2007; 2009). Dados coletados pela autora.

Nessa tabela, perceber-se a queda no número de matrículas na educação infantil estadual e federal e um crescimento na municipal, o que está de acordo com os preceitos da Constituição Federal que estabelece os municípios como responsáveis pela educação infantil e parece demonstrar bem o processo de municipalização da educação básica, além da pouquíssima presença da União na educação infantil.

Há um crescimento significativo de matrículas, de 111.496, em 1996 para 222.191, porém a partir de 2007 vê-se uma queda significativa nas matrículas da pré-escola, o que está relacionado com a lei 11274/2006 que amplia o ensino fundamental para 09 (dos 6 aos 14 anos), retirando da educação infantil as crianças de 6 anos de idade - e, em alguns casos, com menos -, ficando responsável pelos educandos de 0 a 5 anos.

Ao analisarmos o número de turmas em 2009 nessa etapa na rede municipal, e dividirmos pelo número de crianças, obtivemos uma média de 18 crianças por turma na creche, enquanto na pré-escola essa relação foi de 20 crianças por turma. A relação não é tão ruim, porém é preciso ter claro que a média disfarça os extremos. Ao comparar a média da rede municipal com a rede estadual e federal verifica-se uma discrepância, no estado: a relação na pré-escola é de 7 crianças por turma, enquanto na rede federal é de 13 e, na creche de 9, isto significa que, além de estarem sendo atendidas por redes diferentes essas crianças têm uma realidade na sala de aula completamente heterogênea, vê-se, claramente, a inexistência de um Sistema Nacional de Educação como já apontado. 
Em relação aos docentes, há um crescimento expressivo na quantidade - como se pode perceber no gráfico 2 -, que é entendível frente ao crescimento da matrícula. É importante ressaltar que na rede pública a maior contratação se deu na rede municipal de ensino.

Gráfico 2 - Número de docentes na educação infantil pública - PR

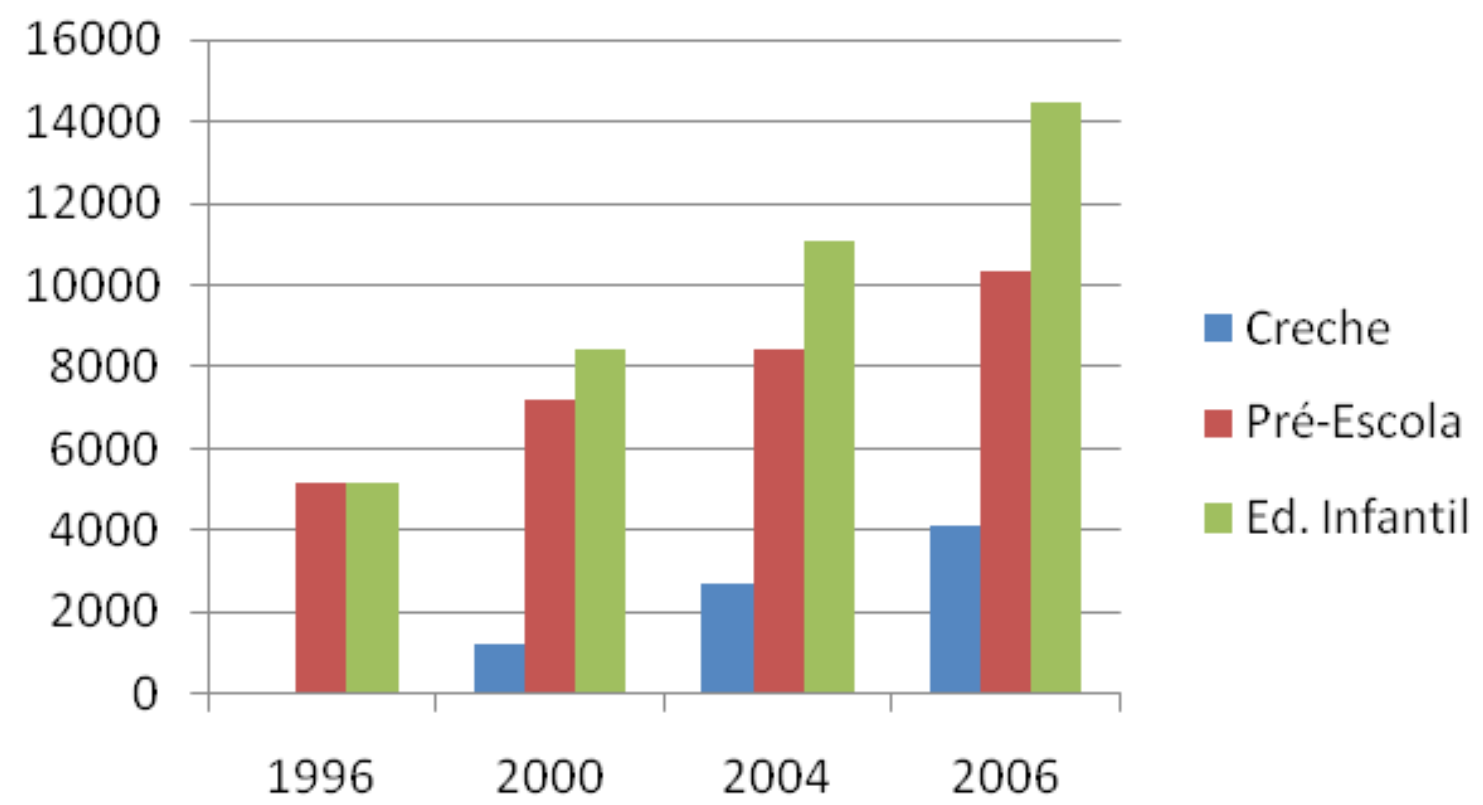

Fonte: Microdados Censo Escolar (1996, 2000, 2004, 2006), dados coletados pela autora.

Porém, mesmo com o crescimento no número de professores, ele é insuficiente, haja vista a relação professor/aluno que, em 2006, na creche municipal era de 22 e 17, na pré-escola. Tal fato se deu porque, na El se trabalhava com muitos profissionais que eram (e ainda são) considerados educadores de criança, mas que não são contratados e nem sempre têm a formação de professores. É o que se configura na Lei de Diretrizes e Bases da Educação Nacional (LDB) que permite o ensino médio com magistério para atuação com crianças de 0-5 anos.

Além do problema com a falta de formação, Corrêa (2007) alerta para a problemática da formação, segundo a autora os cursos de formação de professores, em pedagogia ou outra área de atuação, deixam muito a desejar no que se refere aos subsídios para os profissionais que atuam com esse público. Para a autora "[...] a preocupação deve-se ao fato de que os cursos de formação de professores, em geral, estão centrados nos problemas e questões relativas às séries iniciais do ensino fundamental, e mesmo assim, de maneira muito genérica". (CORRÊA, 2007, p. 29).

Ao refletir sobre a realidade paranaense fica a preocupação com a realidade brasileira, uma vez que o sul do Brasil, assim como o Sudeste, em geral, apresentam melhores condições sociais e educacionais. A análise de tais dados reflete o descaso da educação brasileira para com a educação infantil a décadas e, ao mesmo tempo, uma tentativa, nos últimos anos, de reversão desse quadro feita, sobretudo, pelos municípios, em geral, os entes federados mais pobres.

O contexto do Ensino Fundamental não é tão preocupante, sobretudo, no que se refere ao acesso. Os números da matrícula paranaense (gráfico 3) apresentam de forma muito clara como se "organizou" o regime colaboração no Estado: a rede municipal ficou responsável pelas séries iniciais e a rede estadual, pelas séries finais. 


\section{Gráfico 3 - Comparativo entre matrículas no ensino fundamental na rede estadual e municipal - PR}

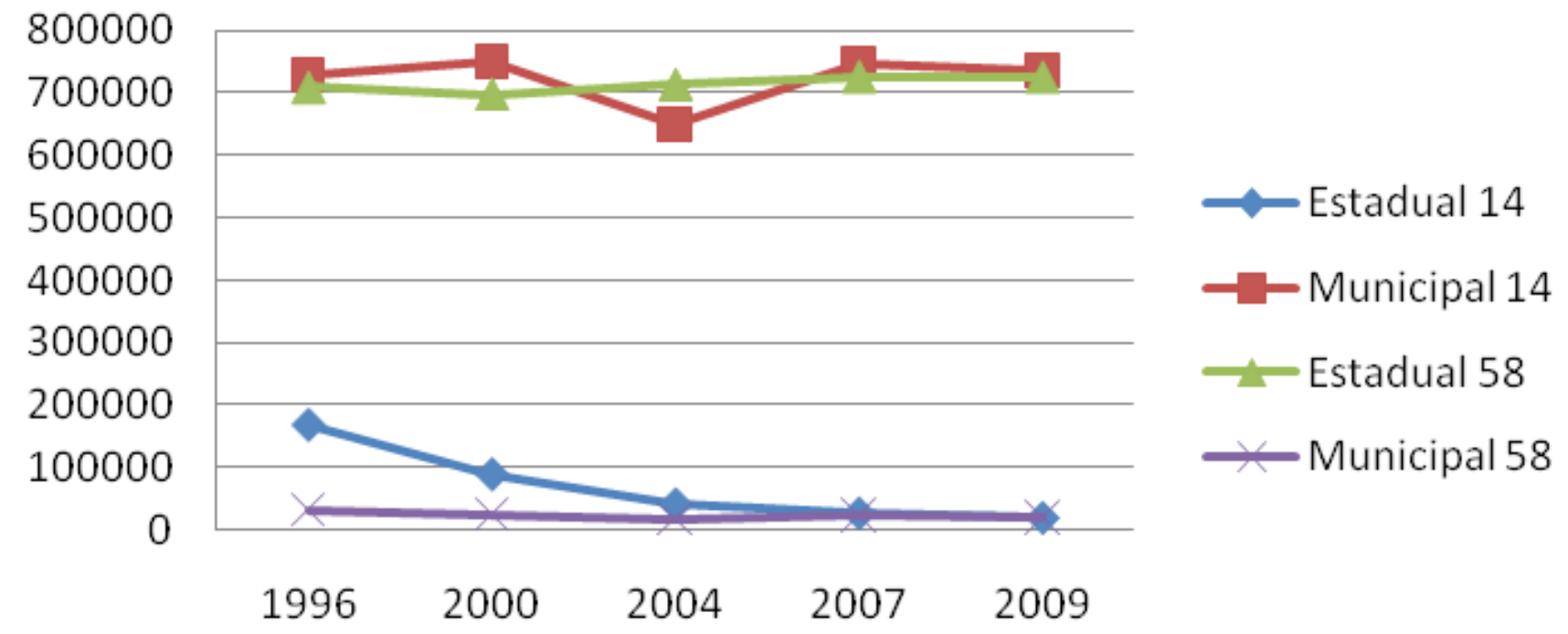

FONTE: Microdados Censo Escolar (1996; 2000; 2004; 2007; 2009). Dados coletados pela autora.

A análise do gráfico aponta o problema na forma de organização do ensino fundamental no Paraná:

[...] para poder concluir o ensino obrigatório, crianças e jovens brasileiros precisam frequentar escolas de diferentes redes de ensino que, em geral, possuem grandes diferenças de qualidade e padrões de avaliação entre si, o que torna mais difícil ainda a conclusão do ensino fundamental com êxito. (PINT0, 2007, p.873)

As transferências das matrículas da rede estadual para a rede municipal ocorreram com mais força no período anterior a 1996, Gouveia et. al. (2001), afirmam que em 1992, 92 (28,6\%) dos municípios paranaenses já tinham firmado um acordo para municipalizar as matrículas. No final desse mesmo ano eram 260 (81,6\%), e, em 1994, 268 municípios (72,2\%) já tinham municipalizado as matrículas da educação infantil e do ensino fundamental das séries iniciais, o que mostra que o processo de municipalização apesar de ser influenciado, fortemente, pelo FUNDEF, já era "semeado" mesmo antes da implementação do fundo (SANTOS, 2001). Assim mesmo, ainda se pode constatar uma queda na matrícula da rede estadual $1^{\mathrm{a}}$ a $4^{\mathrm{a}}$ série de 1996 até 2007, impulsionada pela política de fundos.

Analisando a forma como se dá a oferta, percebe-se, assim como na educação infantil uma discrepância no atendimento no que se refere ao número de alunos por turma, a média das redes municipais é de 34,02 nas séries iniciais e de 29,5 para as finais, a média da rede estadual é de 24,41 para as séries inicias e 30,15 para $5^{a}$ a $8^{a}$ (MICRODADOS CENSO ESCOLAR, 2009). A resolução aprovada pelo CNE no ano passado, referente ao Custo Aluno Qualidade Inicial (CAQUI), apresenta como mínimo de qualidade para as escolas brasileiras, a relação de 24 alunos por sala de aula na fase I do EF e de 30, na fase II. Ao que parece às redes municipais estão um pouco distante desse padrão no que se refere às séries iniciais. O Estado, cuja prioridade não é a primeira fase do EF parece chegar mais perto desse patamar, afinal atende um número reduzido de alunos, apenas 19.291 de um universo de 1.501 .519 só na rede pública.

Não se pode falar de indicadores de qualidade sem comentar sobre a questão docente, o número de docentes no ensino fundamental vem aumentando na rede pública, sendo registrado no ano de 2006 o contingente de 83.828 professores na rede pública, sendo a maior parte deles contratado pelo Estado, como se percebe no gráfico 4. 


\section{GRÁFICO 4 - PORCENTAGEM DE DOCENTES NA REDE PÚBLICA - PR}

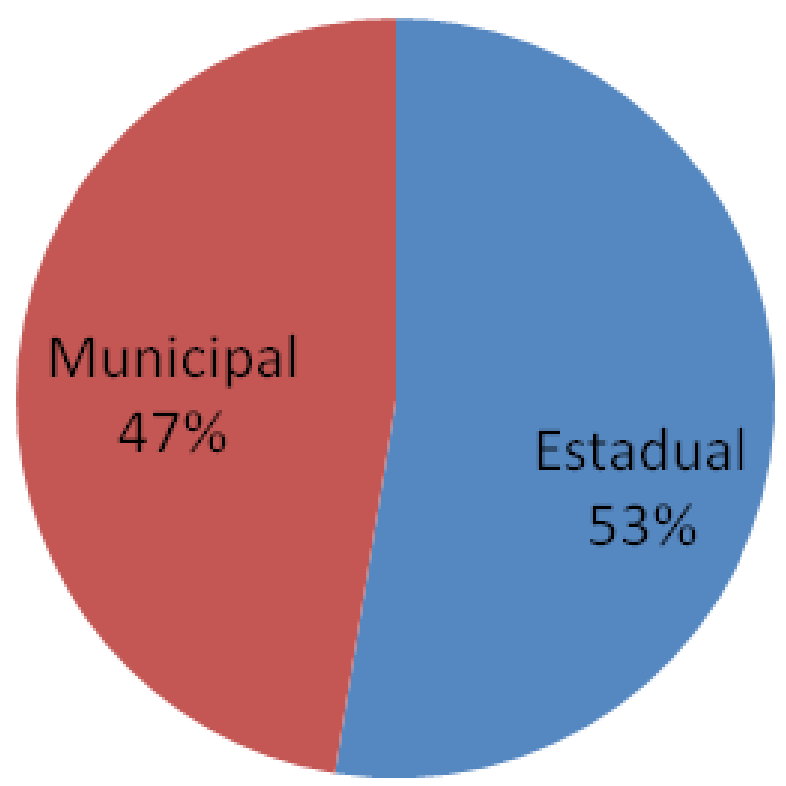

FONTE: Microdados Censo Escolar (2006), dados coletados pela autora.

Relacionando o número de alunos por professor, em 2005, verifica-se uma relação de 20, na rede municipal, das séries iniciais e 18, na rede estadual. Já nas séries finais a relação é de 17 e de 18, no município. Ainda que o número não pareça muito elevado, é preciso levar em conta que esse valor não significa que as salas só tenham este número, primeiro porque se está lidando com médias e segundo não se pode esquecer os professores de área específicas, como educação física, artes, religião.

Ainda em relação aos professores é importante salientar que no Estado do Paraná, muitos professores não são concursados, trabalham por meio de um processo seletivo, simplificado, os PSS como são conhecidos. Segundo Souza (2010)

[...] lecionavam ao final de 2009, nas escolas públicas paranaenses, 64.278 professores, sendo 16.985 (26\%) contratados em regime especial, através de Processo Seletivo Simplificado (PSS), número que se revela preocupante; uma vez que contraria a Constituição da República Federativa do Brasil de 1988, que prevê a admissão de professores temporários apenas para o atendimento de necessidades temporárias de excepcional interesse público. (SOUZA, 2010, p.4).

A problemática dos PSS não atinge só o Ensino Fundamental, mas também o ensino médio. Esta etapa de ensino, segundo Pinto (2007), precisa resolver algumas questões centrais para constituir sua identidade: "a quem se destina" e "qual sua finalidade", tem apresentado um crescimento significativo nos últimos anos, o que pode estar relacionado a uma pressão devido a um número maior de concluintes no ensino fundamental. Vieira (2009) e Pinto (2007), porém, alertam que boa parte dos estudantes do Ensino Médio está fora da idade correta.

No gráfico 5 é perceptível que, conforme a Constituição Federal e a LDB, a responsabilidade pelo EM no Estado do Paraná, seja basicamente da rede estadual, com uma pequena participação da rede federal e, menor ainda, da rede municipal. Em 2009, estavam matriculados nessa etapa 421.909 alunos, entretanto muitos desses jovens já deveriam ter concluído o EM. Além disso, Pinto (2007) aponta que ainda é elevado o número de evasões e reprovações na etapa em questão. 


\section{Gráfico 5- Comparativo entre matrículas no ensino médio na rede pública - PR}

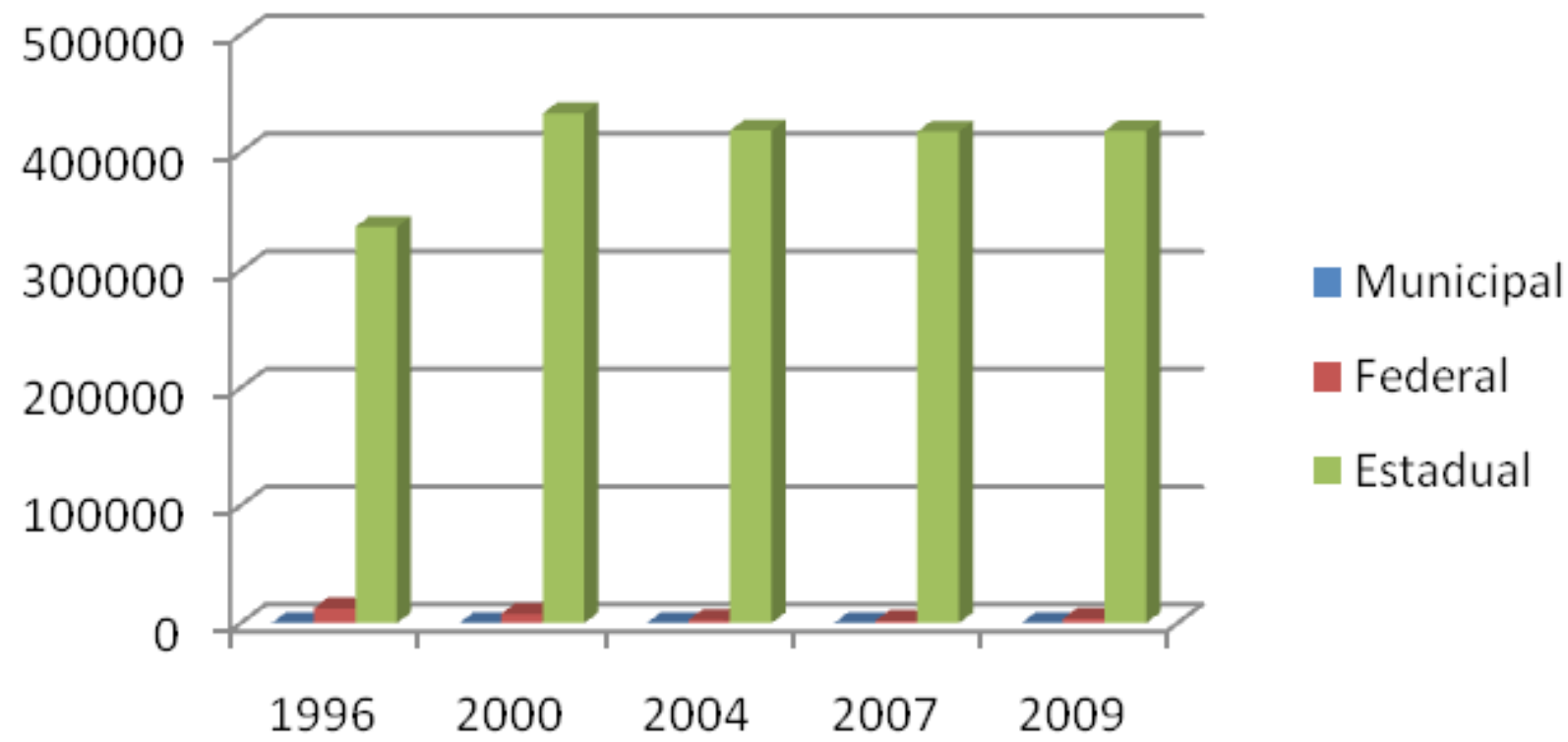

FONTE: MICRODADOS CENSO ESCOLAR (1996; 2000; 2004; 2008; 2009). Dados coletados pela autora.

A relação aluno/turma não parece ser muito problemática no Ensino Médio, segundo dados de 2009 têm-se a seguinte situação:

Tabela 2 - Comparativo turmas e matrículas no ensino médio - PR

\begin{tabular}{|c|c|c|c|c|}
\hline Rede & Número de turmas & Matrículas & Relação aluno/turma & Estabelecimentos \\
\hline Federal & 96 & 3792 & 39,5 & 15 \\
\hline Estadual & 13271 & 418117 & 31,5 & 1341 \\
\hline Municipal & 0 & 0 & 0 & 0 \\
\hline Particular & 1862 & 60010 & 32,2 & 419 \\
\hline
\end{tabular}

FONTE: Microdados Censo Escolar (2009) (dados coletados pela autora).

Chama a atenção o fato de a rede estadual ter a menor relação aluno/turma, e, ao mesmo tempo, o menor número de matrículas, contudo é preciso considerar que se está fazendo uma média. Ao mesmo tempo, é interessante pensar, que ao menos, na média, a rede estadual está melhor que as outras duas redes, afinal ela é, em geral, considerada a mais precária. O CAQUI estabelece uma relação de 30 alunos por turma para o Ensino Médio, ao que parece às escolas do Paraná não estão muito distantes desse patamar.

Em relação ao número de estabelecimentos, a rede estadual representa $74 \%$ do total, contra $25 \%$ da rede particular e $1 \%$ da rede federal. Com, essa constatação, pode-se novamente retomar a ideia de que a União não se responsabiliza pela educação básica, haja vista que sua participação em todas as etapas de ensino é muito insignificante, e o dinheiro repassado por ela por meio do FUNDEF e agora FUNDEB ainda é insuficiente.

Ao dividir o número de alunos pelo total de estabelecimentos, obtêm-se uma média de 252,8 de alunos por escola na rede federal, 311,79 na rede estadual e 143,2 na rede particular. Ao que parece, as escolas estaduais apresentam maior porte em relação às demais redes.

Tratando-se do professor, assim como nas outras etapas analisadas, percebe-se um crescimento no número de professores desde 1996, em 2006 a rede federal contava com 340 docentes, o que representa uma relação 
de 11 professores por aluno, já a rede estadual contava com 29.060, contendo 14 professores por aluno e a rede particular com 5.939 de docentes, obtendo uma relação de 10 professores por aluno, nesse caso, também, é a rede estadual que tem a pior condição.

\section{Considerações em relação à educação básica paranaense}

Observa-se na educação básica do Paraná uma discrepância no atendimento educacional, que vai do número de alunos por turma, da relação docente, da quantidade de estabelecimento, que demonstram a desigualdade no atendimento e explicitam a inexistência de um Sistema Nacional de Educação, afinal as diferenças não estão apenas presentes em termos de Brasil, mas no mesmo estado e, às vezes, na mesma cidade com escolas de redes diferentes e, na maior parte das vezes, de concepções, de estrutura e de qualidade dispares.

Essas diferenças parecem dificultar a consolidação da educação básica, que precisa ser articulado para garantir uma sólida formação ao educando, afinal "[...] a educação infantil é à base da educação básica, o ensino fundamental é o seu tronco e o ensino médio é seu acabamento, e é de uma visão do todo como base que se pode ter uma visão consequente das partes." (CURY, 2002, p.70).

É visível, ao verificar a descentralização das matrículas da Educação Infantil e do Ensino Fundamental para os municípios, que, muitas vezes, a escola não tem condições físicas e financeiras para se manter. Não é por acaso, que haja uma demanda excessiva nas creches e nas pré-escolas. É claro, a forma como se estabeleceu a divisão de responsabilidades por meio do regime de colaboração no Paraná: Estados e Municípios se dividem frente à demanda da educação básica e da União participa por meio de programas complementares (FNDE, por exemplo).

É importante ver o crescimento das matrículas e o aumento do número de docentes, porém, ainda é preciso avançar para conquistar uma educação que seja de direito e de qualidade para todos.

\section{REFERÊNCIAS BIBLIOGRÁFICAS}

ARELARO, L.G; KRUPPA, S. P. Educação de Jovens e Adultos. IN: OLIVEIRA, R.P; ADRIÃO, T. (orgs). Organização do ensino no Brasil: níveis e modalidades a Constituição Federal e na LDB. São Paulo: Xamã, 2007, p. 85-106.

ARELARO, 2007. FUNDEF: Uma avaliação preliminar dos dez anos de sua implantação. Anped, 2007. (Mimeo)

ARAUJO, L. O FUNDEB. Disponível em: http://rluizaraujo.blogspot.com. Acesso em: 08/09/09

CENSO ESCOLAR. Brasília: INEP, 1996. Disponível em www.inep.gov.br. Acesso em: 03/03/10.

CENSO ESCOLAR. Brasília: INEP, 2000. Disponível em www.inep.gov.br. Acesso em: 03/03/10.

CENSO ESCOLAR. Brasília: INEP, 2004. Disponível em www.inep.gov.br. Acesso em: 03/03/10.

CENSO ESCOLAR. Brasília: INEP, 2005. Disponível em www.inep.gov.br. Acesso em: 03/03/10.

CENSO ESCOLAR. Brasília: INEP, 2006. Disponível em www.inep.gov.br. Acesso em: 03/03/10.

CENSO ESCOLAR. Brasília: INEP, 2007. Disponível em www.inep.gov.br. Acesso em: 05/08/10.

CENSO ESCOLAR. Brasília: INEP, 2008. Disponível em www.inep.gov.br. Acesso em: 25/10/10.

CENSO ESCOLAR. Brasília: INEP, 2009. Disponível em www.inep.gov.br. Acesso em: 25/10/10.

CORREAA, B. C. A Educação Infantil. In: OLIVEIRA, R.P; ADRIÃO, T. (orgs). Organização do ensino no

Brasil: níveis e modalidades a Constituição Federal e na LDB. São Paulo: Xamã, 2007, p. 13-30.

CURY, C. R. J. A Educação Básica no Brasil. Educação e Sociedade, Campinas, vol. 23, n. 80, setembro/2002,

p. 168-200. Disponível em http://www.cedes.unicamp.br. Acesso em: 10/01/2010.

Sistema Nacional de Educação: desafio para uma educação igualitária e federativa. Educação e 
Sociedade., Campinas, vol. 29, n. 105, p. 1187-1209, set./dez. 2008. Disponível em <http://www.cedes.unicamp. br. Acesso em: 10/12/2010.

DAVIES, N. FUNDEB: A REDENÇÃO DA EDUCAÇÃO BÁSICA? Educação e Sociedade, Campinas, vol. 27, n. 96 - Especial, p. 753-774, out. 2006 Disponível em http://www.cedes.unicamp.br. Acesso: 10/12/10

FERREIRA, E. \& OLIVERIA, D. A. Crise da Escola e Políticas Educativas. Belo Horizonte: Autêntica, 2009. GOUVEIA, A. B; et. al. O FUNDEF e a democratização da Educação Básica no Paraná. In: GOUVEIA, A. B.; SOUZA, A. R. O financiamento da Educação e o FUNDEF no Paraná. Curitiba: UFPR, 2001, p. 37-50.

OLIVEIRA, R. P. de. Uma dimensão avaliativa do FUNDEF: a desigualdade regional. Educar. Curitiba: Editora da UFPR, n. 22, p. 139-151, 2003.

PERONI, V. Política educacional e papel do Estado no Brasil dos anos 90. São Paulo: Xamã, 2003.

PINTO, J. M. R. A política recente de fundos para o financiamento da educação e seus efeitos no pacto federativo. Educação e Sociedade, Campinas, vol. 28, n. 100 - Especial, p. 877-897, out. 2007 Disponível em http://www.cedes.unicamp.br. Acesso em: 12/12/10.

O ensino médio. In: OLIVEIRA, R.P; ADRIÃO, T. (orgs). Organização do ensino no Brasil: níveis e modalidades a Constituição Federal e na LDB. São Paulo: Xamã, 2007, p. 13-30.

ROMANELLI, O. de O. História da educação no Brasil. 9a Ed. Petrópolis: Vozes, 1987.

SANTOS, J.M.T.P. A municipalização do ensino no Estado do Paraná: história, herança e desafios. In: GOUVEIA, A. B.; SOUZA, A. R. O financiamento da Educação e o FUNDEF no Paraná. Curitiba: UFPR, 2001, p. 37-50.

SAVIANI, D. Sistema Nacional de Educação: conceito, papel histórico e obstáculos para sua construção no Brasil. ANPEd: Caxambu, 2008.Disponível: www.anped.gov.br. Acesso: 01/12/2010.

SOUZA, A. R. de; DAMASO, A. F. Análise das políticas educacionais na oferta de educação infantil na região metropolitana de Curitiba e Litoral do Paraná. Jornal de Políticas Educacionais. Curitiba: NUPE/UFPR, vol.1, n.2, 2007, p.32-40.

SOUZA, M. N. Estado, funcionalismo público e precariedade laboral no Brasil: o caso do professor temporário da rede estadual pública do Paraná. Texto de qualificação: UFPR, 2010 (mimeo).

VIEIRA, S. L. Educação Básica: Política e gestão da escola. Brasília: Liber Livro, 2009. 